\title{
Palliative care is not just for those who are dying
}

Ana Todorovic reflects on the things that helped her when facing the death of her unborn daughter Nadia

\section{Ana Todorovic}

"There is no easy way to say this, but your baby is very, very sick." I was 37 weeks pregnant, and they had just found our baby had severe dilated cardiomyopathy. The doctor thought she would die within days. He suggested injecting potassium in her heart, to be certain that she would not survive terribly impaired.

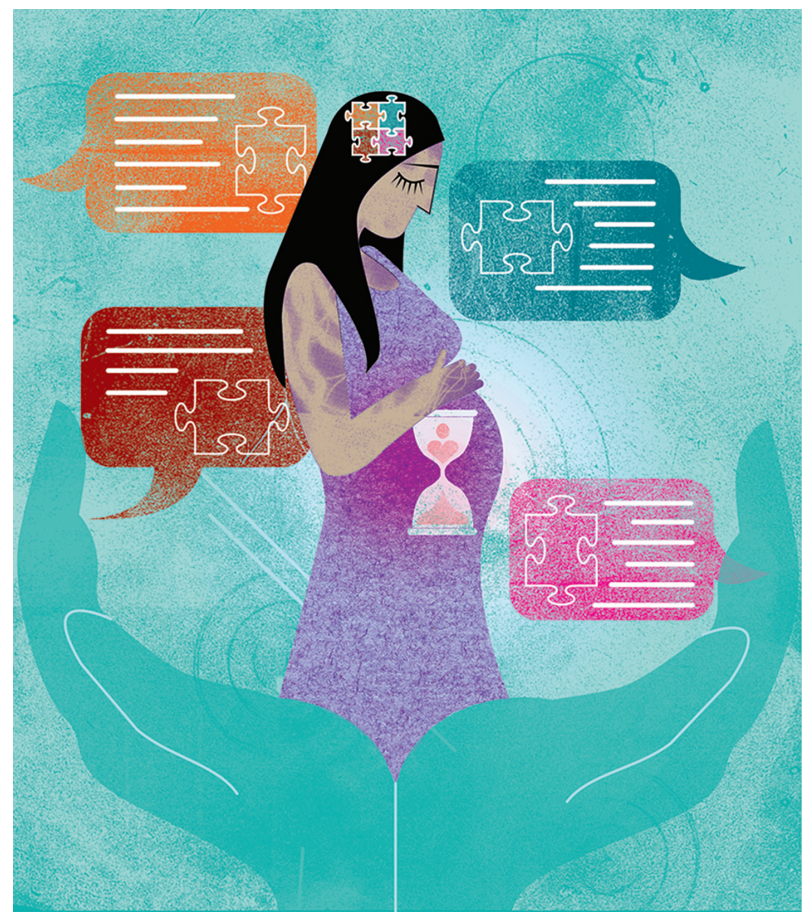

[Image: Rose Lloyd]

She kicked and squirmed inside me as I tried to wrap my mind around this, stunned with shock. It made no sense to take action. Could we not simply let her die in peace? He said this was not an option. But later-perhaps because I asked—we found palliative care mentioned in the discharge note.

\section{Palliative care}

And so at our next appointment we were greeted by two paediatricians who wanted to talk to us. They asked us what was going on. It felt natural to tell them our story. They listened intently, and I realised the purpose of this questioning much later: they wanted to get a sense of us first.

"What would you like to happen?"

I choked up in tears. I hadn't told anyone about my wish to meet her, to hold her while she was dying. They said my wish was common, and a knot of tightness in my chest unravelled.

"And what do you fear most?"

I was afraid how this would affect my relationship with my partner. He feared that our son might develop the same heart condition.

"What would you like to know?"

What she will look like when she's born, if she's not alive. I desperately needed to know all the details.

\section{Precise information}

One of the doctors echoed my words back to me before responding. Then he slowly, gently, answered. She would be swollen, especially her belly, but she'd otherwise look like any other infant. She might not breathe once the umbilical cord was cut. She might not survive the delivery. His words were precise, straightforward, no nonsense, and his approach soft, and this combination resonated with our need to know things, but at the same time to be sheltered from the blows of this knowledge.

Both doctors referred to our baby Nadia by name, showing us they knew how real she was to us.

The male doctor asked if I had considered having the birth induced earlier, to increase the chances of spending some time with Nadia. To have her birth induced while she was still alive. I really wanted that.

The other doctor said that parents experience this short time spent with their terminally ill infants as meaningful and important. She explained how Nadia would be fed and her pain relief administered. Precise words again. "Keeping her comfortable," the most common sentence we encountered when inquiring about palliative care, was too vague for me.

"Both doctors referred to our baby Nadia by name, showing us they knew how real she was to us."- Ana Todorovic 


\section{Allowing grief}

The doctors were at ease with our tears. In the space of a couple of hours they had transformed what we were going through from something dreadful to something potentially meaningful. Nadia died a week later, minutes before she was born. But I was braced for it, and I spent the time after delivery holding her while she was still warm. I got to know my daughter as much as anyone could have known her, and this meant the world to me.

Competing interests: I have read and understood BMJ policy on declaration of interests and declare the following: none.

Published by the BMJ Publishing Group Limited. For permission to use (where not already granted under a licence) please go to http://group.bmj.com/group/rights-licensing/ permissions 


\section{What you need to know}

Remember to offer palliative care side by side with other options when death is imminent, even for newborns

Precise statements in combination with a gentle tone work better than vague statements to cushion the blows surrounding death or illness

When infants die, allow grieving parents to make sense of their child through affectionate contact during this short, precious time 